14,19

\title{
Общность термодинамических свойств кристаллов нормальных длинноцепочечных алифатических соединений и полиметилена
}

\author{
(C) B.М. Егоров, В.А. Марихин \\ Физико-технический институт им. А.Ф. Иофрфе РАН, \\ Санкт-Петербург, Россия \\ E-mail: victor_egorov1@inbox.ru
}

(Поступила в Редакцию 24 января 2018 г.)

Проведен анализ температуры плавления молекулярных кристаллов с разной длиной цепи в зависимости от габитуса элементарного обьема фазового перехода первого рода. Показано, что одинаковое химическое строение „сердцевины“ молекулярных кристаллов - нормальных парафинов $\left\{\mathrm{CH}_{3}\left(\mathrm{CH}_{2}\right)_{n} \mathrm{CH}_{3}\right\}$, диолов $\left\{\mathrm{COH}\left(\mathrm{CH}_{2}\right)_{n} \mathrm{COH}\right\}$, нормальных спиртов $\left\{\mathrm{CH}_{3}\left(\mathrm{CH}_{2}\right)_{n} \mathrm{COH}\right\}$, насыщенных карбоновых $\left\{\mathrm{CH}_{3}\left(\mathrm{CH}_{2}\right)_{n} \mathrm{COOH}\right\}$ и дикарбоновых $\left\{\mathrm{COOH}\left(\mathrm{CH}_{2}\right)_{n} \mathrm{COOH}\right\}$ кислот, при количественном увеличении повторяющихся групп $-\mathrm{CH}_{2}-$ теряют свои индивидуальные свойства и эволюционизируют в полиэтилен (ПЭ).

DOI: 10.21883/FTT.2018.07.46136.021

Настоящая работа является продолжением цикла работ, посвященных изучению влияния типа концевых групп на структуру и свойства длинноцепочечных молекулярных кристаллов (ДМК). Последние вследствие их монодисперсности и отсутствия химических дефектов являются удобными модельными объектами для решения таких дискуссионных вопросов, как влияние длины цепи и типа концевых групп на особенности структурообразования в процессе кристаллизации и структурных трансформаций при фазовых переходах. Особенно важными становятся исследования ДМК по сравнению с обычными полидисперсными и химически дефектными полимерами при установлении количественных обобщающих закономерностей взаимосвязи структура-свойства.

В наших предыдущих работах был выполнен количественный анализ фазовых переходов в модельных гомологических рядах длинноцепочечных н-алканов [1,2], н-спиртов [3], алкано-диолов [4-7], моно- и дикарбоновых кислот $[8,9]$. Надмолекулярная структура перечисленных выше ДМК состоит из нанокристаллических пластин (ламелей) толщиной в единицы $\mathrm{nm}$, сопоставимой с длиной цепи, и имеющих трехмерно-упорядоченную „сердцевину“ из выпрямленных $\mathrm{CH}_{2}$-отрезков и поверхностные слои из различных концевых групп $\left(-\mathrm{CH}_{3},-\mathrm{OH},-\mathrm{COOH}\right)$.

Поскольку „сердцевину“ молекулярных кристаллов образуют метиленовые последовательности из одних и тех же повторяющихся групп $-\mathrm{CH}_{2}-$, в этих соединениях реализуется определенная последовательность по степени усиления взаимодействия концевых групп - от сил вандерваальсового взаимодействия (группы $-\mathrm{CH}_{3}$ для парафинов и спиртов) до т. н. „специфического“ взаимодействия с образованием водородных связей (группы $-\mathrm{COH} \mathrm{для} \mathrm{спиртов} \mathrm{и} \mathrm{диолов} \mathrm{и} \mathrm{группы}-\mathrm{COOH}$ для карбоновых кислот). Концевые гидроксильные группы располагаются на базальных плоскостях ламеллярных кристаллов, образуя двумерные слои и протяженные „полимерные“ цепочки из водородных связей. Это приводит к существенному увеличению торцевой поверхностной энергии этих кристаллов и, как следствие, к изменению их термодинамических характеристик, в том числе температур плавления. В то же время при количественном увеличении числа повторяющихся групп $-\mathrm{CH}_{2}-$ в сердцевине ламелей молекулярные кристаллы будут терять свои индивидуальные свойства и эволюционировать к свойствам полиметилена (ПМ), поскольку объемная составляющая энергии, обусловленная когезионным взаимодействием между метиленовыми транспоследовательностями в кристаллических сердечниках ламелей и пропорциональная длине этих последовательностей, будет возрастать, а величина поверхностной энергии для каждого из перечисленных выше ДМК будет оставаться неизменной.

Изменение термодинамических характеристик ДМК, например, температуры плавления $T_{m}$, в зависимости от $n$, приведено на рис. 1 . Эти данные получены методом дифференциальной сканирующей калориметрии для всей совокупности ДМК при варьировании числа повторяющихся групп $-\mathrm{CH}_{2}-$. Из этих данных следует два очевидных вывода: 1) увеличение торцевой поверхностной энергии приводит к повышению температуры плавления ламеллярных кристаллов с одинаковым $n$; особенно в области $n \leq 20 ; 2$ ) увеличение $n$ приводит к нелинейному росту $T_{m}$.

Нелинейный рост $T_{m}$ объясняется т.н. „размерным эффектом“", характерным для малых частиц, к которым можно отнести наноразмерные ламели ДМК. Отличия в фазовом состоянии малых частиц обусловлены различными внутренними причинами, между которыми существует определенная взаимосвязь [10-12]. „Размерный эффект" выражается, в частности, в смещении температур фазовых переходов, в том числе, температур плавления. Это смещение по температуре $(\Delta T)$ зависит от нескольких факторов и в общем виде определяется выражением $\Delta T / T_{0}=\gamma \cdot K / \Delta H \cdot \rho \cdot R$, где $\gamma$ - поверх- 


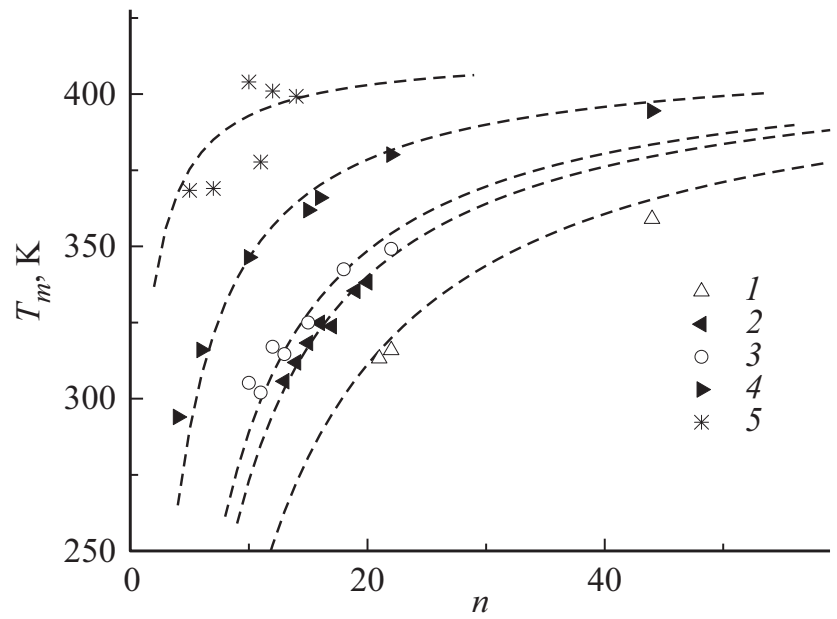

Рис. 1. Зависимость температуры плавления $\left(T_{m}\right)$ длинноцепочечных молекулярных кристаллов (ДМК) от числа метиленовых групп -CH- $(n)$. Обозначения: 1 - парафины; 2 - спирты; 3 - карбоновые кислоты; 4 - диолы; 5 - дикарбоновые кислоты.

ностная энергия; $\rho-$ плотность кристалла, $\Delta H-$ энтальпия перехода; $R$ - характерный размер малой частицы или толщина тонкой пленки; $K-$ коэффициент формы; $T=T_{0}-T_{m}$, где $T_{0}$ и $T_{m}-$ температуры фазового перехода в массивном материале и малой частице соответственно.

Для ДМК это выражение можно записать в общем виде

$$
T_{m}=414.5 \cdot(1-A / L)
$$

где $L$ - толщина ламели, равная $L=0.1273 \cdot n ; n-$ число атомов углерода в молекулярной цепи; $0.1273 \mathrm{~nm}-$ величина проекции связи $\mathrm{C}-\mathrm{C}$ на ось молекулы, $A-$ параметр, учитывающий поверхностную энергию, плотность кристаллического сердечника ламели и энтальпию перехода. Последние два параметра в первом приближении можно считать общими и независящими от $n$ для всей совокупности рассматриваемых в данной работе ДМК, поскольку „сердцевину“ молекулярных кристаллов образуют метиленовые последовательности из одних и тех же повторяющихся групп $-\mathrm{CH}_{2}-$.

Как видно из рис. 1, температуры плавления различных молекулярных кристаллов удовлетворительно укладываются на зависимости, построенные по соотношению (1). При этом значения параметра $A$ оказались равны: для дикарбоновых кислот 0.95; диолов 2.25; карбоновых кислот 4.15; спиртов 4.68 и парафинов 7.3. Из приведенных данных для параметра $A$ видно, что вместо предполагаемого увеличения поверхностной энергии по мере усиления взаимодействия концевых групп в соответствие с уравнением (1) - от сил вандерваальсового взаимодействия до т.н. „специфического“ взаимодействия с образованием различных типов водородных связей, мы наблюдаем кажущееся уменьшение поверхностной энергии для сравнимых по длине молекулярных кристаллов. Этот вывод следует из предположения, что кристаллическую структуру в молекулярных кристаллах образуют единичные ламели. Однако, если ламели наслаиваются друг на друга, сохраняя дальний кристаллографический порядок и образуя более толстые „эффективные“ кристаллы, то наблюдаемый эффект можно объяснить несоответствием между толщиной единичной ламели $L$, использованной при расчете по соотношению (1) и построении графика на рис. 1, с фактической (,эффективной“6) толщиной $L^{*}$, превосходящей величину $L$ в несколько раз.

Для того, чтобы найти связь между параметрами $L$ и $L^{*}$, необходимо рассмотреть энергетику фазового превращения и найти баланс между объемной и поверхностной энергиями при образовании зародышей новой фазы.

Такая работа была проведена при исследовании методом ДСК формы пиков теплоемкости твердофазного (структурного) перехода I рода [13]. Количественный анализ формы пиков на основе теории размытых фазовых переходов позволил определить объемы гетерогенных нанозародышей новой фазы $\Omega$, флуктуационно возникающих на дефектах в исходной фазе и обеспечивающих постепенное распространение межфазной границы при переходе $[14,15]$. Было показано, что в зависимости от соотношения торцевых и боковых поверхностных энергий кристаллов ДМК габитус (форма) зародышей новой фазы меняется от нанопризматической формы (н-алканы) до нанофибриллярной, формы, охватывающей стопку из 6-7 наслоенных ламелей (дикарбоновые кислоты). Этот эффект обусловлен типом симметрии упаковки как молекул в ламелях, так и ламелей в стопках, а также образованием димерных водородных связей между соседними ламелями [13]. Оказалось, что фактическая толщина ламели определяется выражением

$$
L^{*}=\omega^{1 / 3} \cdot\left(E_{k n} / E_{k 1}^{2 / 3},\right.
$$

где $E_{k 1}$ и $E_{k n}-$ энергии когезии метиленовой группы и концевых групп, соответственно. В настоящей работе используются значения энергии когезии, приведенные в монографии [16] для вкладов от $\mathrm{CH}_{2}-$ групп $E_{k 1}=3.6 \mathrm{~kJ} / \mathrm{mol} ; \mathrm{CH}_{3}$-групп $E_{k 2}=4.14 \mathrm{~kJ} / \mathrm{mol}$; водородной связи $\mathrm{COH}-г$ рупп $E_{k 3}=13.4 \mathrm{~kJ} / \mathrm{mol}$ и димерной водородной связи СООН-групп $E_{k 4}=26.8 \mathrm{~kJ} / \mathrm{mol}$. Принимая минимальную из указанного ряда поверхностную энергию для парафина за единицу, была получена следующая последовательность значений $L^{*}$ : парафины $\left(L_{1}^{*}=1\right)$, спирты $\left(L_{2}^{*}>1.5\right)$, карбоновые кислоты $\left(L_{3}^{*}>1.7\right)$, диолы $\left(L_{4}^{*}>3.0\right)$, дикарбоновые кислоты $\left(L_{5}^{*}>6.9\right)$.

На рис. 2 представлены зависимости температуры плавления $T_{m}$ для всех исследованных ДМК от числа $(n)$ повторяющихся групп $-\mathrm{CH}_{2}-$, содержащихся в ламелях с фактической толщиной $L_{1-5}^{*}$. Из рисунка видно, что экспериментальные точки укладываются на единую зависимость $T_{m}(n)$, построенную по соотношению (1) для 


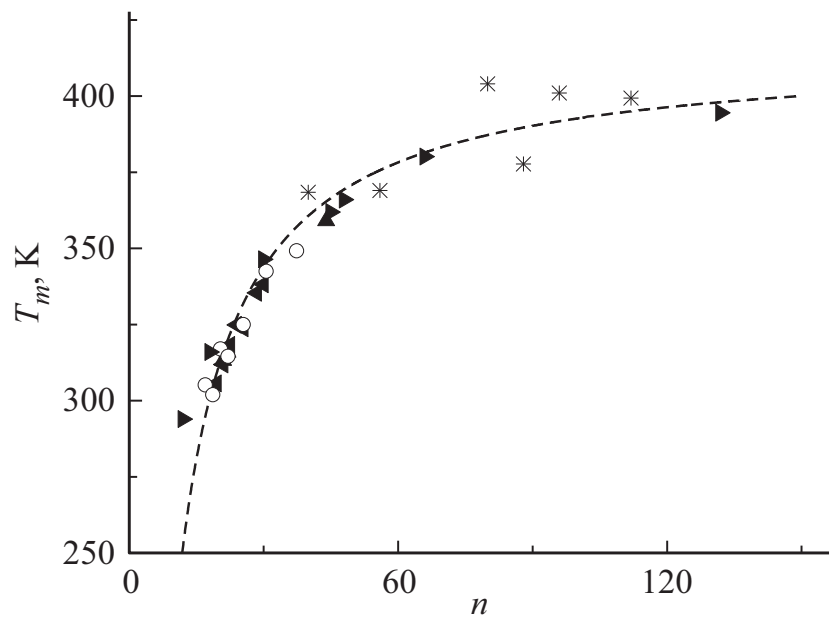

Рис. 2. Зависимость температуры плавления $\left(T_{m}\right)$ длинноцепочечных молекулярных кристаллов (ДМК) от числа метиленовых групп $-\mathrm{CH}-(n)$, содержащихся в ламелях с фактической толщиной $L_{1-5}^{*}$. Обозначения см. рис. 1 .

парафинов. Т. е. зависимость $T_{m}=f(n)$, построенная исходя из принципа баланса внутренней и поверхностной энергий кристаллических ламелей, является общей для разных по химическому строению ДМК.

Выше отмечалось, что молекулярные кристаллы при количественном увеличении числа повторяющихся групп $-\mathrm{CH}_{2}-$ должны потерять свои индивидуальные свойства и эволюционировать к свойствам полиметилена. При исследовании плавления и кристаллизации ламелярных полимерных кристаллов (в частности, полиэтилена и полиметилена) широко используется уравнение Томсона-Гиббса $[17,18]$, аналогичное соотношению (1)

$$
T_{m}=T_{0}\left[1-2 \gamma / \Delta H_{0} \cdot \rho \cdot L_{0}\right]
$$

В качестве размерного параметра при этом используется толщина ламели $\left(L_{0}\right)$, торцевая поверхностная энергия $(\gamma)$, энтальпия $\Delta H_{0}$ и температура плавления $T_{0}$ равновесного бесконечного кристалла. Для полиэтилена $\Delta H_{0}=290 \mathrm{~J} / \mathrm{g}, T_{0}=414.5 \mathrm{~K}[19]$. Боковой поверхностной энергией при этом пренебрегают, поскольку при достаточно больших поперечных размерах ламели площадь торцевой поверхности значительно больше боковой поверхности. Поскольку молекулярные кристаллы сочетают в себе как черты частиц малых размеров, для которых наблюдается фазовый размерный эффект, так и „полимерной“ ламелярной надмолекулярной структурой с наноразмерной толщиной ламелей, использование уравнения Томсона-Гиббса для молекулярных кристаллов требует, помимо учета поверхностной энергии, оценки реальных толщин $L^{*}$ эффективных макрокристаллов стопок из ламелей.

В работе [19] проанализированы данные по температуре плавления ламелярных кристаллов полиэтилена для широкого круга объектов - неориентированных образцов, закристаллизованных из расплава и выращенных из раствора. Эти данные в виде зависимости $T_{m}$ от величины, обратной толщине ламели, представлены на рис. 3. Как видно из рисунка, экспериментальные точки ложатся на прямую, уравнение которой $T_{m}=414.2\left[1-6.27 / L_{0}\right] \pm 0.8 \mathrm{~K}$. Экстраполяция этой прямой приводит к $T_{m}=414.2 \mathrm{~K}$, соответствующей равновесной температуре плавления кристаллов из вытянутых цепей высокомолекулярного полиэтилена.

На этом же рисунке представлены данные по $T_{m}$ для ДМК в координатах обратной толщины $L_{1-5}^{*}$. Эти данные значительно расширяют диапазон рассматриваемых размеров ламелярных образований. Можно видеть, что точки удовлетворительно укладываются на прямую, описывающую поведение ламелярной структуры полиэтилена. Наибольшие отклонения от прямой наблюдаются для самых коротких цепей ДМК, включая дикарбоновые кислоты.

Эти отклонения связаны, по-видимому, с тем, что универсальное межмолекулярное взаимодействие (ММB) метиленовых групп $-\mathrm{CH}_{2}-$ между собой в коротких цепях при температурах ниже $T_{m}$ нарушено. Причиной нарушения универсального ММВ может быть влияние концевых групп $\left(-\mathrm{CH}_{3},-\mathrm{OH},-\mathrm{COOH}\right)$, которые создают большие стерические затруднения для регулярной внутриламелярной упаковки метиленовых групп и образуя при этом своеобразную дефектную слоевую структуру. В этом случае переход в кристаллическое состояние и восстановление универсального взаимодействия метиленовых групп между собой может происходить либо при более низких температурах, либо не происходить вообще. Кристаллические сердечники ламелей этих соединений образуют мезофазу, подобную жидкокристаллическому состоянию $[3,8,9]$.

Из соотношения (2) видно, что при уменьшении $E_{k 1}$ величина $L^{*}$ будет расти, а точки на рис. 3 , отстоящие от экстраполяционной прямой, будут приближаться к ней. Для более точного определения уменьшения $E_{k 1}$

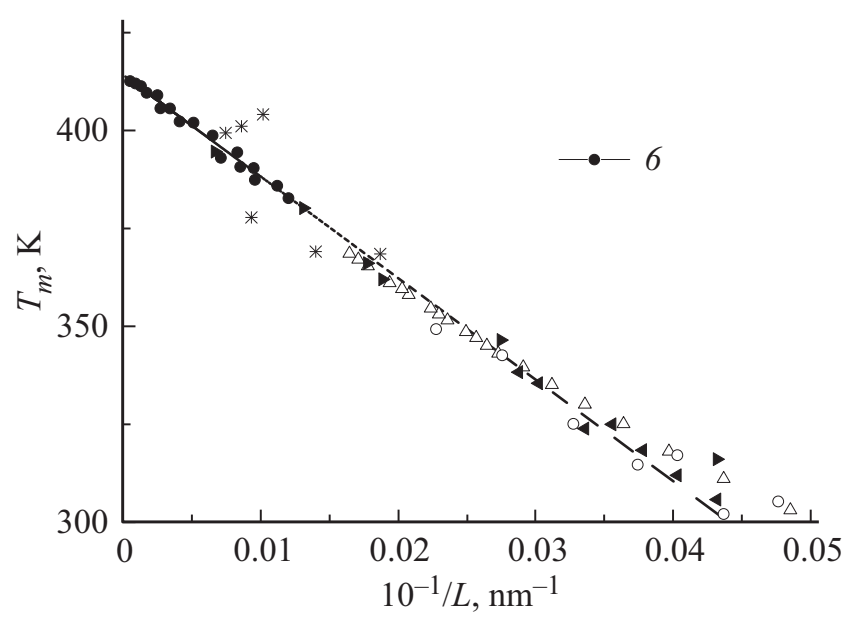

Рис. 3. Зависимость температуры плавления $\left(T_{m}\right)$ полиэтилена [19] и длинноцепочечных молекулярных кристаллов (ДМК) от толщины ламели. Обозначения см. рис. $1 ; 6-$ полиэтилен (ПЭ). 
и расчета величины $L^{*}$ в этом случае необходимы дополнительные экспериментальные данные по энтальпии твердофазного перехода, предшествующего плавлению.

В заключении можно отметить, что отмеченный выше эффект образования в малых частицах промежуточных фазовых состояний, обычно не наблюдаемых в массивных материалах, позволяет выявить родство между ДМК и высокомолекулярным полимером. Наличие в ДМК твердофазного структурного перехода первого рода как составляющей процесса плавления позволит в дальнейшем проанализировать кинетику образования „зародышей“ новой фазы при плавлении и рассмотреть процесс распространения фазовой границы.

\section{Список литературы}

[1] В.М. Егоров, В.А. Марихин. ФТТ 58, 2482 (2016).

[2] В.М. Егоров, В.А. Марихин, Л.П.Мясникова, П.Н.Якушев. ФTT 59, 2044 (2017).

[3] В.М. Егоров, В.А. Марихин, Л.П. Мясникова. ФТТ 50, 126 (2008).

[4] В.М. Егоров, В.А. Марихин, Л.П. Мясникова. ВМС 48(А), 2151 (2006).

[5] В.М. Егоров, В.А. Марихин, Л.П. Мясникова, N. Nakamura. ФTT 51, 2006 (2009).

[6] В.М. Егоров, В.А. Марихин, Л.П. Мясникова. ВМС 47(В), 2191 (2005).

[7] В.М. Егоров, В.А. Марихин, Л.П. Мясникова. ВМС 49(А), 2182 (2007).

[8] В.М. Егоров, В.А. Марихин, Л.П. Мясникова. Высокомоляр. соединения 53, 10, 1722 (2011).

[9] В.М. Егоров, В.А. Марихин, Л.П. Мясникова. ФТТ 55, 975 (2013).

[10] Н.Т. Гладких, С.В. Дукаров, А.П. Крышталь, В.И. Ларин, В.Н. Сухов , С.И. Богатыренко. Поверхностные явления и фазовые превращения в конденсированных пленках. ХНУ им. В.Н. Каразина, Харьков (2004). 276 с.

[11] А.И. Гусев. Наноматериалы, наноструктуры, нанотехнологии. Наука, М. (2007). 416 с.

[12] A.I. Gusev, A.A. Rempel. Nanocryst. Mater. Int. Sci. Publ. (2004). 351 p.

[13] В.М. Егоров, В.А. Марихин. ФТТ 58, 2269 (2016).

[14] Б.Н. Ролов, В.Э. Юркевич. Физика размытых фазовых переходов. Изд-воРостов. ун-та, Ростов н/Д (1983). 317 с.

[15] Г.А. Малыгин. УФН 171, 187 (2001).

[16] А.А. Аскадский, Л.К. Колмакова, А.А. Тагер, Г.Л. Слонимский, В.В. Коршак. Высокомоляр. соединения 19А, 5, 1004 (1977).

[17] J.I. Lauritzen, J.D. Hoffman. J. Res. Nature Stand., 64A, 73 (1960).

[18] J.D. Hoffman, J.J. Weeks. J. Res. Nature Stand., 66A, 13 (1962)

[19] Б. Вундерлих. Физика макромолекул. Мир, М. (1984). Т. 3. $484 \mathrm{c}$.

Редактор Д.В. Жуманов 